\title{
Research and other evidence in practice: the importance of our professional discourse and social relationships
}

\author{
Dominic Hurst \\ Deputy Editor
}

Evidence, it is argued, comes in many forms including research, clinical experience, patient experience and information from the local context ${ }^{1}$ and the process by which these different sources of evidence are blended into a decision is usually nonlinear and complex. ${ }^{2}$ The sources of information are numerous though conversations with colleagues we trust feature commonly in most studies. ${ }^{3-5}$

The justification for attempting to identify and integrate high quality clinical and population-based research into our decisions is based on the assumption that in doing so we will improve the outcomes for our patients. ${ }^{6}$ If we assume the premise to be true then the difficulty arises how to facilitate its uptake by ourselves, our colleagues and the organisations we work for. Barriers to change of any sort in any environment abound and no less so in attempts to get research into practice. ${ }^{7-10}$

It is possible that the day-to-day use of research in decision-making will eventually become more widespread as the concept itself follows the diffusion of innovations curve proposed by Everett Rogers ${ }^{11}$ in which some clinicians adopt the concepts early, the majority join a little later and a few join very much later or not at all. Certainly there seems to be more talk about evidence-based practice, with undergraduate and postgraduate courses incorporating more or less EBD teaching.

But does teaching students the five-step process of ask, search, appraise, apply and evaluate bring about change in practice? There doesn't seem to be much evidence that it does in itself.

Good decision-making is likely to involve much more than just knowing how to find and appraise high quality evidence.

Ethnographic work in general medical practices by John Gabbay and Andree Le May $^{2}$ found that well regarded clinicians made decisions that were not usually very far from that which the research recommended. They showed that these decisions were rarely informed by a conscious search for research evidence.

Instead research found its way into the decision-making of clinicians via many routes, was shared often verbally in chats or meetings, and helped to form the collective norms that the practices developed. Importantly, though, the other evidence sources mentioned at the start of this piece also contributed to the 'good' decisions these doctors made.

Stephen Kemmis argues that changing practice is not just about the practitioner (or student) but about the way in which discourses are constructed (the practice norms, if you like) and the social relationships clinicians build. ${ }^{12}$

If we accept that the use of research in decision-making can be beneficial then I think we need - at the organisational level of dental schools, deaneries, royal colleges, corporates and independent practices - to go beyond training individuals to use a fivestep approach to evidence-based practice and to think much more widely about the context within which we hope the research will make a difference.

The first thing is to recognise that research is but one evidence source amongst many others when we make decisions. However, that shouldn't mean it is easily written off and always trumped by experience. Instead, in the places where we work, we need to encourage the conversations and develop the relationships that will mean useful research becomes part of the evidential melee in our context.

1. Rycroft-Malone J, Seers K, Titchen A, Harvey G, Kitson A, McCormack B. What counts as evidence in evidence-based practice? J Adv Nurs 2004; 47: 81-90.

2. Gabbay J, Le May Ae. Practice-based evidence for healthcare: clinical mindlines. Abingdon: Routledge 2011.

3. Clarke MA, Belden JL, Koopman RJ, et al. Information needs and information-seeking behaviour analysis of primary care physicians and nurses: a literature review. Health Info Libr / 2013; 30: 178-190. PubMed PMID: WOS:000325930900002.

4. Coumou HC, Meijman FJ. How do primary care physicians seek answers to clinical questions? A literature review. J Med Libr Assoc 2006; 94: 55-60. PubMed PMID: 16404470. Pubmed Central PMCID 1324772.

5. Wardh I, Axelsson S, Tegelberg A. Which evidence has an impact on dentists' willingness to change their behavior? / Evid Based Dent Pract 2009; 9. 197-205. PubMed PMID: 19913734.

6. Sackett DL, Rosenberg WM. The need for evidencebased medicine. J R Soc Med 1995; 88: 620-624. PubMed PMID: 8544145. Pubmed Central PMCID: 1295384. Epub 1995/11/01. eng.

7. Richards D. Evidence-based dentistry - The London Symposium. Evid Based Dent 2000; 2: 3-4.

8. van Dijk N, Hooft L, Wieringa-de Waard M. What are the barriers to residents' practicing evidence-based medicine? A systematic review. Acad Med 2010; 85: 1163-1170. PubMed PMID: 20186032.

9. Zwolsman S, te Pas E, Hooft L, Wieringa-de Waard $M$, van Dijk N. Barriers to GPs' use of evidencebased medicine: a systematic review. Br / Gen Prac 2012; 62: e511-e521. PubMed PMID: 22781999. Pubmed Central PMCID: 3381277.

10. Cabana MD, Rand CS, Powe NR, et al. Why don't physicians follow clinical practice guidelines? A framework for improvement. JAMA 1999; 282 1458-1465. PubMed PMID: 10535437.

11. Rogers EM. Diffusion of innovations. 5th ed. New York, N.Y.: Simon \& Schuster, 2003.

12. Kemmis S. Knowing practice: searching for saliences. Pedagogy, Culture \& Society 2005; 13 : 391-426.

Evidence-Based Dentistry (2014) 15, 34.

doi:10.1038/sj.ebd.6401017 